\title{
DAMPAK INTERNET GAMING DISORDER TERHADAP STATUS KOGNITIF DAN PERILAKU PSIKOPATOLOGIS
}

\author{
Marlaokta*, Rika Mutiara \\ Fakultas Kedokteran, Universitas Lampung \\ *marlaoktaph@gmail.com
}

\begin{abstract}
ABSTRAK
Internet Gaming Disorder atau IGD merupakan suatu fenomena yang muncul akibat dari ketidakmampuan mengontrol penggunaan internet dan video games dan sangat popular saat ini. Sejak tahun 2012, lebih dari 1 miliyar orang memainkan internet atau video games. Saat ini IGD sudah resmi dimasukkan sebagai gangguan dalam sistem diagnostik umum (DSM-5). Penelitian ini bertujuan untuk menganalisis gambaran perilaku remaja dan gangguan status kognitif, seperti hambatan aktivitas, gangguan tidur, dan kestabilan emosi. Metode dilakukan dengan menggunakan review artikel dari tahun 2009-2019 yang menggunakan 2 kelompok percobaan, diantara kelompok kontrol dan kelompok pasien pengidap internet gaming disorder. Kedua kelompok tersebut dilakukan pemeriksaan status kognitif dan gambaran perilaku menggunakan kuosioner dan wawancara. Hasil berbagai penelitian yang dilakukan menunjukkan pengaruh yang kuat antara IGD dan gangguan status kognitif, emosi serta perilaku. Simpulan penelitian adalah terdapat pengaruh antara IGD dengan perilaku psikopatologis seperti interpersonal sensitivity, depresi, kecemasan, paranoid, dan gangguan tidur serta berdampak pada penurunan gangguan fungsi kognitif, terutama pada domain atensi.
\end{abstract}

Kata kunci : internet gaming disorder, status kognitif, perilaku psikopatologi

\section{THE IMPACT OF INTERNET GAMING DISORDER TO COGNITIVE STATUS AND PSYCHOPATHOLOGICAL BEHAVIOR}

\begin{abstract}
Internet Gaming Disorder is a phenomenon that arises due to inability to control the use of internet and video games, and has become a topic very popular. Since 2012, more than 1 billion people have played interned or video games. Internet Gaming Disorder officialy included in the third section of the latest (fifth) edition of the Diagnostic and Statistical Manual for Mental Disorders (DSM-5). This study aims to analyze adolescent's behavior, cognitive status disorder, such as activity barriers, sleep disorder, and emotional stability. The method is analyzing the articles from 2009-2019 that used 2 experimental groups, between the control group and the IGD group. Both groups were examined cognitive status and behavioral description using questionnaires and interview. The result of various studies showed a strong correlation between IGD and cognitive status, emotional and behavior. The conclusion of the study, that there is a correlation between IGD with psychopathological behavior such as interpersonal sensitivity, depression, anxiety, paranoid, and sleep disturbance, experience disorder of cognitive impairment, especially in the attention domain.
\end{abstract}

Keywords : internet gaming disorder, cognitive status, psychopathological behavior

\section{PENDAHULUAN}

Internet Gaming Disorder (IGD) merupakan salah satu gangguan mental yang saat ini masuk dalam bagian ketiga dari edisi kelima Manual Diagnostik dan Statistik untuk Gangguan Mental (DSM-5). Game online merupakan fenomena permainan yang sangat populer sejak tahun 2012 dimana lebih dari satu miliar orang memainkan internet game (Kuss, 2013). IGD merupakan keadaan patologis dari penggunaan internet gaming secara berkepanjangan (Morahan, 2010). Beberapa penelitian menunjukkan kondisi ini banyak ditemui di dalam kasus-kasus kesehatan terutama di negara-negara Asia dan beberapa negara bagian Amerika (DSM-5, 2013).

Kuss dan Griffiths (2013) menjabarkan adiksi sebagai bentuk keterikatan secara mendalam 
pada suatu objek (dalam kasus ini adalah internet gaming) dan memengaruhi kognitif, emosi, dan perilaku yang menyebabkan kerusakan signifikan dalam area berbeda di dalam kehidupan nyata mereka. Griffiths (DSM-5, 2013) berpendapat bahwa proses biopsikososial sangat memengaruhi perkembangan adiksi, seperti yang terjadi di dalam internet gaming addiction.

Kuss, dkk. (2012) menjelaskan bahwa internet gaming addiction berhubungan dengan berbagai macam simptom psikofisiologis dan psikiatri dengan berbagai macam dampak negatif. IGD dalam DSM-5, berkesinambungan dengan beberapa dampak negative, diantaranya mengganggu aktivitas tidur, merusak kehidupan nyata, pekerja, sosialisasi, pendidikan, dan juga hubungan. Obsesi dalam internet gaming menimbulkan agresivitas, hambatan hubungan dalam kehidupan nyata, stress, prestasi akademik rendah, masalah memori verbal, merasa sendirian dan tidak Bahagia, disfungsional koping. Selanjutnya, dapat terjadi dampak psikosomatis diantaranya masalah tidur dan lain-lain.

Rata-rata diperlukan waktu 8 sampai 10 jam atau lebih per harinya dan sekurang-kurangnya 30 jam dalam seminggu. Bila seseorang tersebut mencoba menahan diri agar tidak menggunakan komputer untuk bermain, mereka akan gelisah dan marah. Mereka cenderung mengabaikan waktu makan dan tidur dalam rentan waktu yang lama. Mereka juga cenderung menolak aktivitas wajib dalam keseharian seperti bekerja, sekolah, atau waktu bersama keluarga (DSM-5, 2013).

Penggunaan waktu yang berlebihan dalam internet gaming merupakan salah satu gejala adiksi internet. Gejala adiksi yang lainnya diantaranya kelelahan, kurang tidur, nilai-nilai memburuk, kinerja buruk, apatisme. Selain itu terkadang ditemukan kemungkinan berkurangnya waktu investasi untuk hubungan sosisal dan aktivitas. Seseorang dengan IGD mungkin berbohong mengenai banyaknya waktu yang digunakan untuk internet gaming atau menyangkal saat mereka memiliki masalah. Mereka cenderung marah (irritable) saat tidak bermain, atau marah kepada mereka yang mengganggu saat sedang bermain game. Kecanduan terhadap internet gaming ini memiliki dua tanda-tanda (simptom) yang pokok yaitu ketergantungan secara psikologis, rasa membutuhkan, modifikasi mood, kehilangan kontrol serta menyebabkan kerugian sebagai dampak dari perilaku kecanduan (Griffiths et al., 2013).

Berdasarkan DSM-5 (2013), internet gaming disorder diindikasikan 5 atau lebih kriteria selama 12 bulan. Kriteria tersebut lebih rinci dijelaskan menjadi: 1) keasyikan dengan permainan internet, internet gaming menjadi aktivitas utama sehari-hari, 2) tanda-tanda menarik diri ketika internet gaming dijauhkan darinya, 3) toleransi, kebutuhan untuk menambah jumlah waktu untuk internet gaming, 4) usaha gagal untuk mengontrol keterlibatan diri di dalam internet gaming, 5) kehilangan ketertarikan terhadap hobi dan kesenangan sebelumnya kecuali internet gaming, 6) berkelanjutan secara berlebihan menggunakan internet gaming meskipun mengetahui dampak psikososial yang ditimbulkan, 7) berbohong terhadap keluarga dan terapis menyangkut lamanya bermain internet gaming, 8) menggunakan internet gaming untuk melarikan diri dari mood negative (seperti merasa tidak berdaya, bersalah, dan cemas), 9) memiliki hubungan yang membahayakan atau hampir kehilangan, pekerjaan, atau kesempatan karir karena keterlibatannya dalam internet gaming. Penelitian lebih lanjut mengenai fenomena Internet Gaming Diorder penting untuk dilakukan mengingat semakin meningkatnya kasus IGD pada era globalisasi saat ini dan masih terbatasnya penanganan kasus IGD yang efektif untuk semua rentan usia.

\section{METODE}

Metode yang digunakan dalam penulisan ini merupakan studi literature review. Sumber pustaka yang digunakan dalam penyusunan literatur ini menggunakan artikel dengan proses pencarian artikel database journal kedokteran psikiatri. Tahun penerbitan artikel yang digunakan adalah tahun 2009 sampai tahun 2019. Jumlah artikel yang digunakan adalah 17 artikel. Penelitian dilakukan secara cross sectional yaitu berarti dilakukan pada suatu waktu tertentu. Instrumen yang digunakan berupa kuosioner untuk menilai karakteristik klinik dan psikologis yang dilakukan secara manual dan terkomputerisasi dengan tes neuropsikologis. Usia rata-rata respomden adalah $15,375 \pm 5,307$ tahun yang belum pernah mendapatkan terapi khusus secara klinis dan psikologis. 


\section{HASIL}

Hasil dari penelitian Medikanto (2019) pada 37 subjek IGD dan 37 subjek normal, penderita IGD di pedesaan Cangkringan mengalami gangguan fungsi kognitif terutama pada domain kalkulasi/atensi. Hasil uji Mann Whitney pada status kognitif menunjukkan tren penurunan rerata nilai kognitif tiap domain terutama domain kalkulasi/atensi $\mathrm{p}=0,000$; dan total kognitif $\mathrm{p}=0,029$. Hasil uji korelasi bivariat dengan variabel luar tidak ditemukan signifikan. Hasil uji multivariat menunjukkan bahwa IGD berkorelasi signifikan dengan status kognitif dengan $B=1,293 ; p=0,024$. Hasil penelitian Mohammad (2017) dari total 81 responden dengan rata-rata usia $18,74 \pm$ 6,86 dengan menggunakan instrument kuosioner, terdapat adanya hubungan signifikan $(\mathrm{p}=0,001)$ antara intensitas bermain game online terhadap terjadinya depresi, stress, social phobia serta gangguan tidur.

Hasil penelitian Lim (2016) terdapat pengaruh antara pasien dengan IGD sebanyak 44 orang dan kelompok kontrol 40 orang. Perbandingan awal pasien dengan IGD terhadap kelompok kontrol yang sehat telah menunjukkan bahwa pasien IGD memiliki lebih banyak gejala depresi dan kecemasan, tingkat impulsif dan kemarahan / agresi yang lebih tinggi, tingkat kesusahan yang lebih tinggi, kualitas hidup yang lebih buruk, dan gangguan penghambatan respons.

Hasil penelitian Torres (2018) pada 31 responden dengan menggunakan kuosioner "Symptom Checklist-90-R" yang berisikan 90 pertanyaan menyatakan adanya pengaruh antara IGD dengan gangguan psikologi dan karakteristik psikologi $(\mathrm{p}=0,442, \mathrm{p}<0,05)$. Responden remaja tersebut rata-rata memiliki skor tinggi pada skala saat penilaian depresi, kecemasan, dan gangguan somatik. Namun, penelitian menunjukkan adanya beberapa gangguan komorbid lain yang berarti bahwa beberapa sampel remaja dengan IGD memiliki profil klinis yang berbeda.

Hasil dari penelitian Mallorqui, et al. (2017) pada 288 pasien yang diberikan kuosioner "Symptom Checklist-90-R" (Derogratis, 1994) berisikan 90 item pertanyaan, didapatkan pengaruh signifikan antara IGD dan gangguan kognitif serta gejala psikiatri, diantaranya interpersonal sensitivity, depresi, kecemasan, paranoid serta atensi.

\section{PEMBAHASAN}

Studi ini membandingkan antara sekelompok responden dengan IGD dan bukan IGD. Dalam beberapa sampel penelitian, kelompok IGD rata-rata berusia muda antara 12 sampai 20 tahun (beserta onset gangguan pada usia muda), cenderung lajang, dan cenderung memiliki tingkat pengangguran yang tinggi dibandingkan kelompok bukan IGD. Hal ini dapat terjadi karena sifat internet game sendiri yang lebih menarik bagi para remaja dan orang dewasa muda serta keberadaan generasi muda saat ini yang cenderung dengan mudahnya mengakses internet setiap hari (Kuss, 2018).

Berdasarkan hasil penelitian, kelompok IGD menunjukkan skor psikopatologis yang lebih tinggi, sifat kepribadian yang kurang fungsional, dan skala kognitif yang lebih rendah dibandingkan kelompok kontrol. Secara umum kedua kelompok ini cenderung memiliki tekanan emosi tinggi yang bersamaan. Pasien IGD mengalami tekanan psikopatologi dengan kecenderungan impulsif. Pada hasil uji status kognitif menunjukkan tren penurunan rerata nilai kognitif tiap domain, terutama domain kalkulasi atau atensi (Medikanto, 2019).

Namun, beberapa hasil penelitian tersebut memiliki beberapa keterbatasan yang perlu untuk dipertimbangkan. Pertama, desain crosssectional penelitian tersebut belum dapat menggambarkan hubungan sebab akibat dan masih harus disesuaikan dengan keadaan masa yang akan datang. Selain itu, kelompok IGD yang dilaporkan cenderung lebih banyak didominasi oleh laki-laki daripada perempuan serta ukuran sampel yang berbeda. Oleh sebab itu, hasil penelitian harus diambil secara hatihati sebelum digeneralisasikan untuk laki-laki dan perempuan (Young, 2011).

Faktor penyebab IGD yang banyak ditemukan adalah sebagai modifikasi mood (sebagai bentuk koping), media untuk melarikan diri, hubungan pertemanan, karakteristik kepribadian, genetik dan fisiologis, serta lingkungan. Internet gaming disorder menyebabkan beberapa risiko diantaranya masalah fisik, pribadi, dan masalah yang berkaitan dengan pekerjaan atau akademik (Torres, 2018). 


\section{SIMPULAN}

Terdapat pengaruh antara internet gaming disorder dengan gambaran perilaku psikopatologis seperti hambatan aktivitas (makan, bersekolah, kerja, dan tidur), interpersonal sensitivity, depresi, kecemasan, dan paranoid. Selain itu IGD berdampak kuat pada penurunan gangguan fungsi kognitif, terutama pada domain atensi.

\section{DAFTAR PUSTAKA}

American Psychiatric Association. 2013. Diagnostic and Statistical Manual of Mental Disorders, Fifth Edition. London: American Psychiatric Publishing Beranuy, M., Carbonell, X., \& Mark, D. G. A Qualitative Analysis of Online Gaming Addicts in Treatment. Int $\mathbf{J}$ Ment Health Addiction, 11, 149-161

Charlton, J. P., \& Danforth, D. W. 2010. Validating the distinction between computer addiction and engagement: online game playing and personality. Behaviour \& Information Technology, 29(6), 601-613.

Delfabro \& Grifiths, MD. 2010. Cognitive Behavior Therapy For Problematic Video Game Players: Conceptual Considerations And Practice Issues. Journal Of Cybertherapy And Rehabilitation.

Dickey, M. D. 2011. World of Warcraftand the impact of game culture andplayin an undergraduate game design course. Computers \& Education, 56, 200-209.

Griffiths \& Kuss. 2009. Diagnosis And Management Of Video Games Addiction. United Kingdom : Notthingham Trent University

Khazaal, Yazeer, et al. 2012. Cognitive Behavioral Treatments for Internet Addiction. The Open Addiction Journal, Vol. 5: 30-35

King, D. L., \& Delfabbro, P. H. 2014. The cognitive psychology of Internet gaming disorder. Clinical Psychology Review, 34(4), 298308. doi:10.1016/j.cpr.2014.03.006
King, P. H., \& Delfabbro, P. 2019. An Introduction to Gaming and IGD. In P. H. King, P. H. Delfabbro, D. King, \& P. Delfabbro (Eds.), Internet Gaming Disorder: Theory, Treatment, and Prevention (pp. 1-21). London: Academic Press.

Kuss DJ, Pontes HM and Griffiths MD. 2018. Neurobiological Correlates in Internet Gaming Disorder: A Systematic Literature Review. Front. Psychiatry 9:166. doi: 10.3389/fpsyt.2018.00166

Lee, J.E. 2011. A Case Study Of Internet Game Addiction. Journal Of Addiction Nursing. $22: 208-213$

Malaby, T. M. 2012. Our Presen Misfortune: Games and the Postbureaucratic Colonization of Contingency. Social Analysis, 56(2), 103116.

Medikanto, Alfi. 2019. Analisis Gangguan Status Kognitif Penderita Internet Gaming Disorder Pada Siswa SMP Di Pedesaan Cangkringan. Yogyakarta: Universitas Gadjah Mada.

Mohammad, Haekal. 2017. Hubungan Intensitas Bermain Game Online Terhadap Terjadinya Stres, Depresi, Social Phobia, Gangguan Tidur Serta Perilaku Agresif. Medan: USU

Tuappatinaja, dkk. 2013. Cognitive Behavior Approach. Workshop : USU

Torres-Rodríguez, A., Griffiths, M. D., Carbonell, X., \& Oberst, U. 2018. Internet gaming disorder in adolescence: Psychological characteristics of a clinical sample. Journal of Behavioral Addictions, 7(3), $707-$ 718. doi:10.1556/2006.7.2018.75

Young, Kimberley S., \& de Abreu, Chistiano Nabuco. 2011. Internet Addiction: A Handbook and Guide to Evaluation and Treatment. Hoboken, New Jersey: John Wiley \& Sons, Inc. 